\title{
Dejando atrás una relación abusiva de pareja: \\ voces y testimonios de mujeres inmigrantes víctimas de violencia machista
}

\author{
Leaving an abusive relationship behind: voices \\ and testimonies of immigrant women victims of sexist \\ violence
}

\author{
MARÍA DEL CARMEN VERA-ESTEBAN* \\ Instituto Universitario de Investigación de Estudios \\ de Género. Universidad de Alicante \\ ORCID ID: 0000-0002-0627-8965 \\ María CRISTINA CARDONA-Moltó** \\ Instituto Universitario de Investigación de Estudios \\ de Género. Universidad de Alicante. \\ ORCID ID: 0000-0001-8132-1161
}

Recibido: 20/07/2020

Aceptado: $12 / 1 / 2021$

doi: https://doi.org/10.20318/femeris.2021.5932

\begin{abstract}
Resumen. La presente investigación pretende dar a conocer las historias y narrativas de un grupo de mujeres inmigrantes víctimas de violencia de género conviviendo en una Casa de Acogida de la Comunidad Valenciana. Asimismo, averiguar el estado en el que llegan a la Casa de Acogida, las barreras que han tenido que sortear para abandonar la relación abusiva y la influencia del apoyo recibido durante su estancia en la misma. Se trata de una investigación cualitativa desarrollada en una entidad social utilizando un diseño de casos múltiple. La entrada a campo se produce a través de un taller de Danza Contemporánea en el que se crea un espacio de conocimiento personal y de comunicación donde las participantes cuentan sus experiencias sin ser juzgadas y liberan la carga emocional reprimida durante largo tiempo. Tras la experiencia, se puede concluir que su llegada a la Casa de Acogida es estresante por el sufrimiento padecido, la incertidumbre y las expectativas erróneas sobre lo que van a encontrar en ella. No obstante, pasado el periodo de adaptación suelen reencontrarse consigo mismas. Se van recuperando y van gestionando sus vidas con las estrategias aprendidas. Consiguen un acercamiento entre madres e hijas/hijos y salen fortalecidas y realizando una valoración positiva del apoyo profesional recibido.

Palabras clave: mujeres inmigrantes, violencia machista, barreras personales y estructurales, recuperación emocional, danza contemporánea.
\end{abstract}

\footnotetext{
*mdcv5@alu.ua.es

${ }^{* *}$ cristina.cardona@ua.es
} 
Abstract. This research aims to present the stories and narratives of a group of immigrant women who have suffered gender violence living in a shelter in the Valencian Community. Also, find out the state in which they arrive at the House, the barriers they have had to overcome in order to leave the abusive relationship and the influence of the support received during their stay there. This is a qualitative investigation developed in a social entity using a multiple case study design. The entry to the field occurs through a Contemporary Dance workshop in which a space of personal knowledge and communication is created and where participants can tell their experiences without being judged and release their repressed emotional charge since long time. After the experience, it can be concluded that the arrival at the House is stressful for this group due to the suffering they carry with them, the uncertainty, the imminent change, and the erroneous expectations about what they will find in the House. However, after the adaptation period they usually find themselves again. They recover and start managing their lives with the strategies learned. They approach their daughters/sons, and leave strengthened and making a positive assessment of the professional support received.

Keywords: inmigrant women, sexist violence, personal and structural barriers, emotional recovery, contemporary dance.

\section{Introducción}

La violencia machista sigue siendo un problema generalizado a nivel mundial que deteriora la salud de las mujeres; rompe la estructura familiar y perpetúa la desigualdad entre ambos sexos. Según el Instituto de la Mujer y para la Igualdad de Oportunidades (2018), la violencia es la fórmula utilizada por los hombres para someter a las mujeres y, de esta forma, perpetuar su dominio sobre ellas y mantener sus privilegios en el hogar, lo cual ocasiona graves daños a las mujeres y a sus hijas/hijos. Para paliar el daño físico y psicológico y como recurso de protección y recuperación hacia las mujeres maltratadas y sus menores, el Estado español ofrece la posibilidad de alojarse en Casas de Acogida, las cuales están reguladas en la Ley Orgánica 1/2004, de 28 de diciembre, de Medidas de Protección Integral contra la Violencia de Género. Esta ley recoge los aspectos preventivos, educativos, sociales, asistenciales, sanitarios y penales reconocidos a las mujeres víctimas con derecho a servicios sociales de atención, de emergencia, de apoyo y acogida y de recuperación integral.

El acceso a las Casas de Acogida es uno de los recursos puestos a disposición de las mujeres que han sufrido maltrato. Existen otros servicios al alcance de las mujeres, tanto españolas como inmigrantes en situación de riesgo y/o exclusión social, a los que pueden acceder dependiendo de cuáles sean sus necesidades. Concretamente, en la Comunidad Valenciana las medidas y recursos establecidos para luchar contra la violencia machista se articulan a través de la Ley 7/2012, de 23 de noviembre, de la Generalitat, Integral contra la Violencia sobre la Mujer en el Ámbito de la Comunitat Valenciana. Esta ley, en su Título II, recoge las medidas de prevención de la violencia contra la mujer en los ámbitos educativo, social y laboral entre las que cabe destacar: medidas de información y sensibilización social, de investigación, de formación y especialización de los profesionales que atienden a las víctimas, de atención psicosocial, jurídica y policial, de personación de la Generalitat en los casos cuyo resultado sea la muerte de la víctima o en aquellos en los que se generen lesiones graves e invalidantes para la misma. Algunos de los servicios comprendidos 
dentro de la Red de la Generalitat de Asistencia Social Integral a las Víctimas de Violencia sobre la Mujer son los recursos de régimen ambulatorio como las Oficinas de Atención a las víctimas del delito, los Servicios de Atención Telefónica Permanente, o los Centros Mujer. Asimismo, la Ley ampara la atención a las víctimas en régimen residencial como los Centros de Emergencia, Centros de Recuperación Integral, o las Viviendas Tuteladas. La Generalitat Valenciana y también el Estado español ofrecen, además, otros recursos de ayuda de carácter general como los Servicios de Información, de Asesoramiento o de Acompañamiento a las víctimas, así como los Puntos de Encuentro familiar.

En general, para que una mujer maltratada por su pareja solicite ayuda ha debido haber pasado por un duro trance, en muchos casos, de años de duración. Según Walker (1979), las mujeres suelen transitar las tres fases del Ciclo de Violencia con diferentes duraciones e intensidades: (1) Fase de acumulación de tensión, en la que comienzan las situaciones indeseadas, discusiones, enfrentamientos, defensa o sumisión que hacen que la hostilidad de pareja crezca y la mujer pierda el control de la situación; (2) Fase de explosión de violencia o fase aguda, en la que el agresor agrede a la víctima psíquica y/o físicamente; cuando acaba esta fase aparece la calma y la mujer queda en estado de shock o no puede creer lo sufrido; (3) Fase de arrepentimiento o "luna de miel", en la que el maltratador se arrepiente de lo sucedido, pide perdón o promete que no va a volver a ocurrir y trata de conquistar a la pareja; la mujer se siente vulnerable; desea que el maltratador cumpla con lo prometido, especialmente, al principio de la aparición de la violencia, lo que establece una dependencia emocional. Más tarde, por la indefensión experimentada se tiende a crear una postura de evitación renunciando a modificar la situación y convirtiéndose en una barrera personal que se ha de superar para acabar con la relación. La decisión de las víctimas de quedarse o abandonar una relación de maltrato viene determinada, según Choice y Lamke (1997), por la ponderación de dos cuestiones: ¿Estaré mejor? y ¿Puedo hacerlo? La decisión se ve influida, además, por una serie de factores que en el caso de mujeres inmigrantes son los riesgos sociales de marcharse como, por ejemplo, sentirse desleal con su cultura o la pérdida de la identidad cultural (Tran y Des Jardins, 2000), el riesgo de ruptura familiar con la consiguiente pérdida de acceso a sus hijos o separación de los hijos de sus padres (Kelly, 2009). En relación a la segunda pregunta ¿Puedo hacerlo?, la investigación apunta a que altos niveles de sentimientos de compromiso y amor, así como la esperanza de que la situación mejorará son las barreras personales más determinantes para evitar el término de una relación de pareja abusiva o iniciar la búsqueda de ayuda a través de los servicios sociales o penitenciarios (Davis, 2002). Para las mujeres inmigrantes, el compromiso se define, a menudo, como un deseo de estar a la altura de un ideal cultural siendo, por ejemplo, una 'buena madre' o una 'buena esposa', más que como apego emocional (Kelly, 2009).

Otras barreras personales identificadas en la investigación como determinantes para terminar una relación abusiva de pareja en mujeres no inmigrantes son las percepciones de sí mismas, especialmente, los sentimientos de baja auto-estima y locus de control externo (Kim y Gray, 2008), así como también el miedo a las repercusiones de un abusador (e.g. miedo a la escalada de la violencia) (Kim y Gray, 2008; Wolf et al., 2003), si bien esas barreras no han sido el foco principal de la investigación con mujeres migrantes. 
La falta de conocimiento de la existencia de servicios de apoyo también ha sido identificada en la investigación como una barrera estructural determinante para abandonar la relación, tanto en mujeres inmigrantes (Keller y Brennan, 2007) como en mujeres no inmigrantes (Lutenbacher et al., 2003; Short et al., 2000). Otras barreras estructurales identificadas en ambos grupos de mujeres incluyen experiencias de discriminación (Bauer et al., 2000; Wolf et al., 2003) y/o falta de recursos económicos (Bauer et al., 2000; Murdaugh et al., 2004; Wolf et al., 2003).

Las mujeres inmigrantes experimentan barreras estructurales adicionales que incluyen barreras de lenguaje (Bauer et al., 2000; Keller y Brennan, 2007) y creencias vinculadas a los roles de género y prácticas culturales tradicionales (Bauer et al., 2000; Keller y Brennan, 2007). Por ejemplo, que la violencia marital/pareja es normal (Latta y Goodman, 2005) o que está prohibido salir de la familia en busca de ayuda (Abu-Ras, 2003). Las prácticas que impiden que las mujeres vayan a la escuela u obtengan un empleo (Abraham, 2000) también son frecuentes.

Aunque la investigación con mujeres inmigrantes y no inmigrantes víctimas de violencia de género ha identificado una serie de riesgos y de barreras personales y estructurales que median en la decisión de abandonar o no la relación abusiva, no ha logrado hasta ahora determinar con precisión cómo estos riesgos y barreras predicen la decisión de dejar una relación de abuso en este colectivo de mujeres. Algunos indicios e indicadores de los riesgos mencionados se desprenden y/o pueden deducirse de las voces y testimonios de las participantes en el estudio que se describe a continuación.

\section{Compartiendo las voces de un grupo de mujeres supervivientes a la violencia de género}

Este estudio nos introduce en las historias y testimonios de un grupo de mujeres maltratadas que conviven en una Casa de Acogida de la ciudad de Alicante, España, en la que han sido acogidas para salvaguardar su vida y la de sus hijas/os. La finalidad de la investigación fue acercarnos al colectivo de mujeres víctimas de maltrato de pareja alojadas en la Casa de Alicante para averiguar en qué estado llegaron y cómo su paso por la misma les había ayudado a mejorar su situación según sus propias narraciones. Para ello, se plantearon los siguientes objetivos:

1. Analizar las historias de las mujeres inmigrantes víctimas de violencia machista que viven en una Casa de Acogida e identificar las barreras que han de sortear en sus trayectorias de vida.

2. Revelar cómo llegan a la Casa y cuáles son sus expectativas.

3. Conocer cómo afecta el tránsito por la Casa de Acogida a las mujeres supervivientes de una relación abusiva de pareja. 
El medio para llegar a ellas fue la organización de un taller de Danza Contemporánea. En el taller se facilita la comunicación a través de la expresión emocional, la liberación de tensión, el conocimiento corporal y el contacto físico como vía de recuperación emocional, aceptación personal y acercamiento social. De acuerdo con Leventhal (1980), la danza favorece el desarrollo emocional y la afectividad restaurando la comunicación con el medio y con otras personas tanto de forma verbal como a través de la expresión corporal, el ritmo, el movimiento y la música.

\section{Método}

\section{Contexto y participantes}

La Casa de Acogida de Alicante es el lugar donde se llevó a cabo este estudio que tuvo una duración de seis meses, desde septiembre de 2018 hasta febrero de 2019. En esta Casa las profesionales trabajan colaborativamente para cubrir las necesidades de las mujeres acogidas ofreciéndoles mediante un trato individualizado intervención social y educativa (e.g. adquisición y/o desarrollo de hábitos personales, maternales y de mejora de la relación con sus hijas/hijos; apoyo psicológico y actividades terapéuticas), intervención y acompañamiento sanitario, asesoramiento jurídico e inserción y formación laboral.

Las participantes fueron un grupo de 15 mujeres víctimas del maltrato machista que convivían en una misma Casa de Acogida. El 100\% eran de origen extranjero y su procedencia era diversa como puede apreciarse en la Tabla 1. Procedían de las regiones de América del Sur, América Central, Europa del Este, Norte de África y Asia Oriental. Su edad

Tabla 1. Mujeres víctimas de maltrato residentes con sus hijas/hijos en la Casa de Acogida.

\begin{tabular}{|l|c|c|c|c|}
\hline \multicolumn{1}{|c|}{ Participante } & Nombre & País de origen & Edad & Hijas/hijos en la Casa de Acogida \\
\hline Caso 1 & Bonia & Senegal & 33 & 1 \\
\hline Caso 2 & Mary & Giorgia & 30 & 2 \\
\hline Caso 3 & Danna & Ecuador & 42 & 0 \\
\hline Caso 4 & Katia & Ucrania & 26 & 1 \\
\hline Caso 5 & Jolette & Venezuela & 27 & 0 \\
\hline Caso 6 & Zazil & Etiopía & 32 & 0 \\
\hline Caso 7 & Silvín & Honduras & 42 & 0 \\
\hline Caso 8 & Cristiane & Venezuela & 22 & 1 \\
\hline Caso 9 & Malina & Rumanía & 31 & 1 \\
\hline Caso 10 & Lucía & Argentina & 26 & 1 \\
\hline Caso 11 & Maisa & Marruecos & 31 & 1 \\
\hline Caso 12 & Tabatha & Colombia & 18 & 0 \\
\hline Caso 13 & Maylín & China & 51 & 0 \\
\hline Caso 14 & Solana & Colombia & 32 & 0 \\
\hline Caso 15 & Lucielé & Cuba & 25 & 0 \\
\hline
\end{tabular}


oscilaba entre los 18 y 51 años, con una media de 31 años (DT = 8.44). El 46\% convivía en la Casa con un hijo/hija menor (una de las mujeres con sus dos hijas), mientras que el 54\% residían solas en la Casa, si bien un $26 \%$ de ellas tenían hijas/os que vivían con familiares o en un centro de atención a menores. El 75\% de las participantes había sufrido maltrato físico y psicológico y casi el $25 \%$ de ellas daban fe de que sus hijos también habían sido maltratados directamente. Normalmente, las mujeres acogidas en estas Casas desean sentirse protegidas lejos del maltratador y comenzar una vida nueva.

\section{Instrumentos}

- Guión de entrevista (profesionales de la Casa de Acogida y participantes). El objeto de las entrevistas semiestructuradas a las profesionales fue conocer su labor en la Casa y recopilar información sobre la realidad del grupo, en general, además de las características y necesidades de cada una de ellas, en particular. Las entrevistas cubrieron estos aspectos quedando abiertas a la incorporación de cualquier información que se considerase relevante para un mejor aprovechamiento del taller. Las entrevistas a las participantes se realizaron para establecer una primera toma de contacto. Se recogió información sobre sus gustos, necesidades y algunos datos personales que voluntariamente quisieron compartir.

- Guión de observación participante. Su objeto fue contemplar los fenómenos, situaciones, acciones, procesos, etc., acontecidos en la sesiones. En él se recogieron ordenados por sesiones: objetivos, contenidos y actividades planificadas.

- Diario de campo. Se utilizó para el registro de notas de campo de tipo descriptivo (sobre lo que lo captado del contexto) y reflexivo (sobre la interpretación y reflexiones acerca de lo observado por parte de la observadora). Se registró y analizó, en cada sesión del taller de danza, sobre los siguientes aspectos: (1) estado emocional de las participantes al comienzo del taller; (2) implicación individual; (3) relación de las participantes entre ellas; (4) capacidad de focalización de la atención; (5) grado de energía empleada en la realización de las actividades propuestas; (6) qué expresan y cómo lo expresaban con sus cuerpos; (7) grado de liberación de tensión y de las emociones a través del movimiento; (8) estado emocional en el que acaban las sesiones; (9) capacidad de comunicación sobre sus experiencias y sobre cómo se perciben; (10) reflexión sobre su propia práctica en las sesiones acerca de: qué piensan, cómo se sienten y qué hacen.

- Cámara de vídeo. Con la que se grabaron algunas de las sesiones.

\section{Procedimiento}

Se contactó con la Casa de Acogida a través de la Dirección Territorial de Vivienda, Obras Públicas y Vertebración de Territorio de la provincia de Alicante. Se informó a la 
Dirección de la Casa del interés en la realización del estudio y se presentó la solicitud pertinente. Conseguida la autorización de acceso y aprobación del estudio, se realizó el primer contacto telefónico con la directora y, tras el consentimiento informado, las primeras entrevistas: una con la directora y otra con la psicóloga y la trabajadora social de la Casa. Estas profesionales aportaron información sobre las participantes y sugirieron pautas a tener en cuenta para contactar adecuadamente con las residentes. Finalmente, se acordó la fecha de entrada a campo que se llevó a cabo en cuatro momentos diferenciados: (1) aproximación y primeras tomas de contacto con las participantes; (2) diseño del plan de intervención; (3) solicitud de consentimiento informado a las mujeres para participar en las sesiones del taller de Danza Contemporánea y registro en el diario de campo de lo observado durante las sesiones; y (4) análisis y valoración de los registros.

\section{Voces y experiencias de las participantes}

Las narrativas siguientes de las mujeres maltratadas son algunos de los ejemplos recogidos que reflejan la labilidad emocional, las creencias y las experiencias vividas por las participantes del estudio. Igualmente, narran sus percepciones acerca del apoyo recibido dentro de la Casa tanto por las profesionales que allí trabajan como por las compañeras que conviven en el centro, así como del Taller de Danza Contemporánea recibido.

Cuando estaba con mi pareja llegué a sentirme muy triste, sin esperanza, muy mal e incluso fea, aunque siempre tuve claro que era él el que no estaba bien y que se equivocaba en las cosas que me decía. (Cristiane)

Yo no soy feliz porque tengo muchos problemas. En mi primer matrimonio tenía de todo y no era feliz y en mi segundo matrimonio no tenía de nada y tampoco he sido feliz. (Lucielé)

El estado de salud de las participantes es diverso. Algunas sufren patologías relacionadas con el maltrato recibido. También la percepción de su estado emocional y de su situación es variopinta en ellas.

Siento una sensación por dentro desagradable, con ojos cerrados me mareo. Me siento débil y mareada, como si mis rodillas me fallasen. Ahora no me veo capaz de poder hacer lo que hacen las demás y me siento triste también por mi debilidad, ... he llorado mucho y no quiero llorar más. (Thabata)

Mi pareja me trataba con mucho cariño y con extremo cuidado y eso me encantaba. Recuerdo la primera vez que me ridiculizó delante de su mejor amigo. Yo me acababa de arreglar y en cuanto me vio me dijo que parecía un loro y se fue. Me lo dijo de una forma muy fea. A partir de ese día hubo muchos más desprecios, agresiones verbales y maltrato psicológico siempre sin ningún motivo. Llegué a pensar que estaba enfermo y quise ayudarle tratando de que fuéramos los dos a un psicólogo, cosa que nunca aceptó. Nuestra relación 
duró casi dos años, fue un calvario absoluto y cuando sentí que mi vida corría peligro lo dejé, desaparecí un buen día que vi la oportunidad y no me llevé nada más que lo puesto, la documentación y un poco de dinero ... al día siguiente sentí como si me hubiera quitado un gran peso de encima, fue una sensación muy liberadora. (Cristiane)

Algunas de las mujeres sienten cierta aversión al tacto debido a que las actividades del taller les recuerdan algún acontecimiento traumático vivido con el maltratador. En las actividades propuestas para introducir el contacto y el uso de la mirada, como componentes para la mejora de las relaciones sociales, las respuestas de las participantes son diversas. Otras mujeres tampoco se muestran capaces de mantener la mirada dirigida a los ojos de sus compañeras de taller durante unos segundos y se muestran reservadas ante su cercanía corporal.

He sentido una sensación muy extraña al notar que varias manos me tocaban a la vez. Al principio no me ha gustado, me he puesto en tensión pero me he dado cuenta y he conseguido aguantar y después me he relajado un poco, así que creo que no me ha venido mal. (Solana)

Desde que estoy aquí no he sentido una zona tan grande en contacto con mi espalda. Antes dormía en contacto con la espalda de mi pareja. Pensé de repente que él estaba aquí y me agobié. Después he conseguido controlar mi angustia y seguir con la actividad. La verdad es que ahora me siento mucho mejor, porque he podido controlar mi temor en ese momento y continuar. (Zazil)

La idea que tienen de sí mismas las participantes (cómo se perciben, cuáles son sus capacidades a la hora de solucionar problemas sobre aspectos de sus vidas, cuál es su situación actual y sus deseos) son algunos de los aspectos reflejados en los testimonios siguientes.

Quiero ser como era antes. Quiero pensar por mí, decidir por mí y reírme cuando yo lo necesite. Con mi segundo marido he estado privada absolutamente de todo y dejé de ser yo misma, pasé a sentirme totalmente anulada y siempre con conflictos. Quiero recuperar lo que he perdido, pero necesito solucionar mis problemas para ser feliz. (Luceilé)

He dedicado mucho tiempo a mis estudios y a mi trabajo y he descuidado por completo mi físico. (Jolette)

En el siguiente testimonio se aprecia claramente la opresión experimentada por esta mujer debido a una de las barreras personales mencionadas que caracteriza a este colectivo (Kim y Gray, 2008) y que no les ayuda a romper con la relación abusiva como es la baja autoestima. Igualmente, el testimonio contribuye a confirmar otra de las barreras estructurales con las que se suelen encontrar las víctimas de violencia machista: el desconocimiento de la existencia de instituciones que les van a proporcionar seguridad y servicios, en este caso, de los servicios sociales (Keller y Brennan, 2007). 
Él me decía que mi nombre era vergonzoso y también me hacía sentir fea. He llegado a sentirme muy fea, como que no valía nada. Yo lo idolatraba, lo veía un hombre muy inteligente que sabía lo que yo necesitaba. Cuando lo conocí me dijo que yo tenía una necesidad muy grande de cariño y que se notaba que antes nadie había sabido dármelo. Al principio se portaba muy bien conmigo y se ganó mi confianza, pero después de poco tiempo, cuando supo cuál era mi situación en España y que no tenía amigos porque hacía poco tiempo que estaba en el país, empezó a aprovecharse de mí. Me amenazaba con denunciarme a la policía para que me expulsaran del país, si no hacía lo que él quería, ... porque yo no tenía los papeles en regla. Me propuso que me fuera con otros hombres para sacarles el dinero y yo lo intenté pero no pude hacerlo, no sirvo para eso. Todo eso me producía enorme tristeza, me sentía sin energía. Al final todo acabó porque me echó de la casa de mala manera. (Silvín)

\section{Llegada a la Casa de Acogida}

Las mujeres maltratas acceden a las Casas de Acogida en la Comunidad Valenciana a través de las gestiones de la Red de Centros Mujer 24 Horas, bajo la supervisión de la Dirección General de Familia y Mujer y de las direcciones territoriales correspondientes de la Comunidad. En esta Casa se les ofrece atención integral especializada a las mujeres víctimas de violencia y a sus hijas/hijos menores que las acompañan. Ingresan habiendo sido dependientes económicamente de su expareja o acceden habiendo perdido el trabajo por lo que esta situación es una de sus mayores preocupaciones. Poseen diferentes niveles educativos y culturales, hecho que afecta directamente a las posibilidades de encontrar un trabajo y a que éste sea mejor o peor remunerado. Según el estudio realizado por VivesCases et al., 2009), con un total de 599 mujeres migrantes víctimas de violencia machista, solo un $28.3 \%$ poseía estudios universitarios, un $39.2 \%$ poseía estudios secundarios y no tenían estudios o solo tenían estudios primarios el 32.5\% de las evaluadas.

Muchas de estas supervivientes llegan con serios problemas emocionales. Algunas padecen graves problemas psicológicos; sufren de un alto grado de ansiedad y depresión o temen por sus vidas. La reexperimentación de los acontecimientos traumáticos al activar de forma inconsciente sus pensamientos es algo común en ellas.

No quiero que me toquéis, no me gusta y ya he hecho bastante con participar tocando al resto de compañeras, ya no quiero participar más. Me resulta desagradable y hago un gran esfuerzo al ser tocada por otras personas. Me siento presionada y por eso he respondido así, ... no puedo continuar porque me siento mal. (Reexperimenta episodios de imágenes $o$ pensamientos que le recuerdan acontecimientos violentos que le producen malestar general y la bloquean). (Lucía)

En algunos casos, desarrollan otras enfermedades derivadas de la situación de maltrato, la cual tiende a empeorar. En el siguiente testimonio se desvela el miedo al agresor como una barrera personal que impide el abandono de la relación abusiva e incluso el poder contar lo que le pasa a un especialista cuando tiene la oportunidad. El miedo perpetúa 
el poder del agresor sobre la víctima y el empeoramiento de la salud de la mujer como sostienen Wolf et al. (2003).

Hoy me encuentro mejor, aunque tengo un poco de sueño porque tomo pastillas para la depresión. Las tomo desde hace cuatro años, cuando conocí a mi marido ... Yo no tengo hijos. Tengo displasia de ovarios. Hace dos años me quedé embarazada, lo supe a los tres meses y a los pocos días de saberlo mi ex me empujó fuertemente, me di con el pico de una mesa y perdí al bebé. Estuve unas tres semanas en cama con mucho dolor, sangré mucho. Mi pareja no quiso llevarme al médico y tampoco me dejaba salir. Él solo quiso que fuéramos cuando ya apenas sangraba. Delante del médico no pude hablar del embarazo, no pude contar nada porque él estaba conmigo. (Reexperimenta y somatiza el suceso al contarlo, manifestándose en su cuerpo mediante palidez, sudoración y mareo, inhabilitándola para continuar con lo que está haciendo). (Luceilé)

Otras mujeres llegan padeciendo el Síndrome de la Mujer Maltratada y mostrando alteraciones psíquicas como el Trastorno de Estrés Postraumático, entendido como la "aparición de síntomas característicos que sigue a la exposición a un acontecimiento estresante y extremadamente traumático en el que el individuo se ve envuelto en hechos que representan un peligro para su vida o cualquier otra amenaza para su integridad física" (Pastor-Bravo, 2015, p. 210). Según la misma autora (2015), las mujeres que han sufrido repetidamente la violencia machista a lo largo del tiempo desarrollan un estado de alerta permanente que deteriora su autoestima, genera depresión y sentimiento de culpabilidad. Algunas de ellas han sufrido una relación anterior de violencia machista con otra persona, incluso en ciertos casos han sufrido abuso sexual dentro de su núcleo familiar durante la niñez.

Antes nunca pensaba en mis emociones, nunca quería ver cómo me sentía ... Cuando era una niña y luego más mayor, cuando me sentía mal porque abusaba de mí, intentaba no sentir, pensaba que estaba en otro lugar, como si no estuviera allí. Luego me sentía mal y siempre estaba enferma. Ahora soy más consciente de que necesito escucharme y atenderme a mí misma sin huir de lo que me pase porque tengo miedo. Tengo que conocerme mejor, descubrir cosas, permitirme sentir mis emociones y cuidarme también. (Bonia)

En algún caso han llegado a la Casa de Acogida en situación de indigencia extrema, por lo que sufren todo tipo de carencias y se sienten incapaces. En general, estas mujeres carecen de iniciativa para realizar ciertas actividades de la vida cotidiana y comportarse de forma asertiva. Según Mestre et al., 2008), cuanto mayor sea el periodo de maltrato mayor irritabilidad e incapacidad mostrarán las mujeres para abordar sus problemas. Como consecuencia de su estado emocional muestran incapacidad también para interactuar con sus hijos, disciplinarles o motivarles. Al no encontrarse bien las madres muestran dejadez, deficiencias en la relación con sus hijas/hijos y esto genera situaciones conflictivas durante la convivencia. Llegan a perder el apego entre madres e hijas/ hijos y las relaciones entre ellos están tan viciadas por los años de sufrimiento que es necesario romper con la dinámica mediante apoyo psicológico y educativo. De acuerdo 
con Echeburúa (2004), el sufrimiento de las mujeres les ha hecho perder su identidad y ante la pérdida aparece el duelo que puede manifestarse en forma de síntomas somáticos (pérdida de apetito, insomnio, síntomas hipocondríacos, etc.) y psicológicos (pena y dolor, fundamentalmente).

Mi hija me domina porque no he sabido poner límites, ahora lo sé, lo reconozco y también que tengo miedo de quedarme sola. Sinceramente, me gustaría cambiar eso y tener una relación mejor con mi hija, pero no es fácil, ... no sé muy bien cómo hacer las cosas para arreglarlo con ella. (Danna)

Muchos de los menores llegan sin escolarizar, se muestran rebeldes y pueden manifestar conductas agresivas. Otros menores han presenciado malos tratos o los han vivido en su propia persona.

Mi hija ha sufrido mucho y ha presenciado la violencia de su padre conmigo. Ahora no se despega de mí, tampoco quiere relacionarse con otras personas. Está demasiado retraída... estoy intentando que se despegue un poco de mí, para que sea más independiente, ... lo estamos intentando. (Malina)

Por lo tanto, los problemas de las mujeres que acceden a la Casa son de todo tipo y principalmente emocionales, de ausencia de empleo y dependencia económica. Por lo general, sus necesidades se pueden abordar mediante apoyo psicológico, de reinserción socio-laboral, sanitario y educativo.

\section{Expectativas de las mujeres en la Casa de Acogida}

Las mujeres, aunque no en su mayoría, llegan con una idea confusa de lo que se les va a ofrecer en una Casa de Acogida. Según Rebollo-Sánchez y Bravo-Campanón (2005), la falta de información o la información confusa e incluso la mala coordinación entre los profesionales, por los que pasan las mujeres antes de entrar en las Casas de Acogida, hacen que tengan una idea distorsionada de lo que van a encontrar o de lo que puedan lograr cuando ya son alojadas. Creen que van a conseguir prestaciones económicas, un trabajo, un piso o una guardería para sus hijas/hijos, pero esto no es así, por lo que pueden sentirse engañadas. Ellas llegan al centro para cuidar de sí mismas y de sus menores, para reflexionar sobre lo que les ha ocurrido y planificar lo que deben hacer con el fin de mejorar su situación siempre con ayuda de las profesionales. Son ellas las que han de dirigir sus vidas y encontrar trabajo y vivienda.

$\mathrm{Al}$ entrar en la Casa se establecen objetivos individualizados, con orientación profesional, los cuales deben ir consiguiendo a lo largo de su estancia. Además, deben tener en cuenta la temporalidad del alojamiento. Ante las falsas creencias debidas a la información errónea recibida sobre las Casas de Acogida, las mujeres encuentran cierta dificultad para aprovechar los recursos que se les ofrecen llegando a creer que no cumplen con sus ex- 
pectativas. Reorganizarse y ser conscientes de su realidad les lleva un tiempo. El informe elaborado por la Asociación pro Derechos Humanos Argituz (2015) señala que las expectativas más comunes de las mujeres maltratadas básicamente son: (1) vivir con sus hijas/ hijos en un lugar seguro protegidos del maltratador; (2) ser apoyadas a nivel económico y conseguir una vivienda; (3) tener mayor apoyo social; (4) recibir protección dentro y fuera de la Casa de Acogida y conseguir mayor vigilancia sobre el agresor; (5) regular su situación de personas inmigrantes; y (6) recibir un trato humano.

Estoy esperando la homologación de mi titulación superior y en cuanto la tenga ya podré buscar trabajo. Espero poder resolver todo el papeleo durante este año y después poder encontrar trabajo y traer a mi hijo. Tengo una amiga de la familia en España que nos alquila una habitación muy económica. (Jolette)

\section{Influencia del tránsito por la Casa de Acogida}

La permanencia en la Casa de Acogida en todos los casos es temporal. Según Mestre et al. (2008), aquellas personas que permanecen alojadas durante más tiempo reducen sus niveles de ansiedad, en cambio en lo que se refiere a la conducta de implicación y de trabajo manifiestan menos interés en esforzarse y tener éxito. La reducción de su ansiedad se debe, principalmente, a que se sienten protegidas, tienen cubiertas sus necesidades básicas y las de sus hijas/hijos y por ello se relajan. También, tras haber vivido durante mucho tiempo un gran desgaste emocional su energía y su capacidad de resolución son mínimas. Conforme pasan los meses, gracias al apoyo de la trabajadora social, la psicóloga y las educadoras van consiguiendo resolver algunos de sus problemas. Los niveles de estrés comienzan a aumentar cuando advierten que pronto acaba su tiempo de permanencia en la Casa, especialmente en los casos que no han conseguido solucionar sus problemas de acceso al trabajo, a la vivienda o al reconocimiento de las ayudas sociales económicas.

Yo estar deprimida, tengo que dejar Casa semana que viene y no tengo trabajo, no tengo casa donde dormir. No sé qué voy a hacer. (Esta participante no ha conseguido crear una rutina que pueda cumplir por sí misma durante su estancia en la Casa; no logra planificar, tampoco es puntual y además es demasiado tranquila en todo lo que hace. No ha conseguido la prórroga de permanencia en la Casa). (Maisa)

De acuerdo con Mestre et al. (2008), durante el período de permanencia en las Casas de Acogida en torno al 15\% de las mujeres consigue un trabajo. Tras la crisis económica del 2008 sufrida en España conseguir un trabajo se convirtió en una misión muy difícil para ellas. En la actualidad, en la mayoría de casos y teniendo en cuenta la realidad económica del país, las limitaciones del idioma y de su escasa formación, las residentes siguen accediendo en un porcentaje similar a trabajos precarios y mal remunerados. 
En las situaciones de maltrato el apoyo social y familiar conforma un factor de protección y de resiliencia, influyendo positivamente en las personas maltratadas y evitando el aislamiento social de las mujeres.

Yo ahora me he dado cuenta de que no necesito a otra persona para hacer ciertas cosas y eso me hace sentir bien, ahora sé que soy capaz de hacerlo yo sola. Necesito conocer personas nuevas y estoy animada para ello. Ahora me toca empezar de cero en otra ciudad y romper con mi pasado. (Malina)

Conforme a Mestre el al. (2008), el apoyo emocional y el trato humano ofrecido a las mujeres es lo mejor valorado por ellas. Al sentirse apoyadas en su paso por este trance y tras recibir atención psicológica individualizada, muestran índices más elevados de autoestima, mayor capacidad para enfrentar su situación y abordar los problemas. La convivencia en la Casa con otras mujeres no siempre es respetuosa y cercana y surgen problemas de convivencia por diversos motivos. Los horarios y la disciplina son dos aspectos difíciles de gestionar para ellas porque les genera estrés debido a la falta de costumbre al haber vivido una vida caótica donde no existía organización.

No me interesa lo que hacen aquí. Varias veces a la semana querer hacer maletas, ir, porque aquí demasiadas normas ... no estoy bien aquí, no me adaptar. (Tal como la informante manifiesta, tiene problemas de adaptación; tampoco intenta llevarse bien con todas las demás, incluso amenaza a una de las participantes). (Katia)

Algunas consiguen aprender a gestionar su tiempo, las tareas de la vida cotidiana, la familia, etc., y son capaces de mantener un orden al abandonar la Casa de Acogida. Otras no lo consiguen, aunque sí mejoran en ello durante el tiempo que permanecen en la Casa.

Cuando llegas a la Casa es muy difícil la convivencia porque todo son normas y venimos de unas situaciones muy difíciles y te encuentras con esto y entonces parece que te vas a volver loca de estar aquí dentro. Te sientes encerrada y si antes de entrar en la Casa pensabas que ibas a estar mejor luego te das cuenta de que no es como pensabas. Es muy difícil también la convivencia con las personas que van llegando o que ya están dentro, cada una con sus problemas, con las que a veces no puedes comunicarte porque hablan otros idiomas o porque no quieren relacionarse ... Yo me he sentido muy apoyada por algunas compañeras y también por las trabajadoras de la Casa. (Mailín)

Al tener que seguir las normas impuestas por el equipo directivo y por las profesionales de la Casa referentes a los horarios, la disciplina o los hábitos de vida saludable, muchas adquieren una rutina que les ayuda en su compromiso con la crianza por lo que comienza a mejorar la relación entre madre e hijas/hijos.

Rebollo-Sánchez y Bravo-Campanón (2005) señalan que tras su paso por la Casa de Acogida las mujeres en su mayoría hacen una valoración positiva del apoyo recibido. 
Gracias a que estoy aquí he podido hablar con la psicóloga y también con otras que están aquí igual que yo. He empezado a entender todo lo que he vivido con mis parejas y a reconocer que no confío mucho en mí misma. Pensaba que un hombre me ayudaría, pero no ha sido así y esto ya no se va a repetir. Sé que tengo que ser más fuerte y confiar más en mí. (Silvín)

Cuando vine me sentía débil, en todo mi cuerpo, ... No tenía energía para poder moverme con libertad, tenía mareos y mi aspecto ... era ... no era saludable. La estancia en la Casa me ha permitido recuperarme aunque soy consciente de mi enfermedad y de que no me recuperaré del todo, pero por lo menos el tiempo que me quede lo pasaré mejor que antes. Mi hija es lo que más me preocupa y el poder pasar más tiempo con ella cuando salga de aquí. (Danna)

El paso por las Casas de Acogida no siempre es garantía de éxito para ellas. En el lado opuesto están aquellas que no logran aceptar su situación porque no siempre es asumible para ellas. Algunas mujeres vuelven con el maltratador e incluso en algún caso abandonan la Casa sin previo aviso.

\section{Taller de Danza Contemporánea con las residentes en la Casa de Acogida}

Como apoyo a las ayudas que reciben las mujeres por parte de la psicóloga y educadoras, y atendiendo a las recomendaciones de estas profesionales, se propuso el taller de danza cuyo propósito fue facilitar la recuperación emocional de las mujeres residentes víctimas de maltrato. Su duración fue de 6 meses y su periodicidad de dos sesiones semanales, cada una de hora y media. Las actividades prácticas diseñadas para estas sesiones se seleccionaron teniendo en cuenta las carencias que presentaban las mujeres.

En el taller se trabajaron los siguientes contenidos: la gestión de la respiración; el conocimiento corporal y sus posibilidades de movimiento; la toma de conciencia corporal y la aceptación del propio cuerpo tal y como es; la alineación corporal; la observación y reconocimiento del estado corporal y mental; la atención guiada y la concentración; la atención dirigida hacia cuerpo-mente y hacia el entorno cercano; el conocimiento y uso del espacio propio, el espacio cercano y el espacio compartido; la visualización guiada, el reconocimiento de las emociones y sus manifestaciones en el cuerpo; la canalización de la expresión de las emociones; la exploración de la liberación emocional y del estado de alegría que produce la práctica de la danza; la modulación de la energía; y la introducción a la improvisación guiada.

Durante las sesiones, se combinaron las metodologías investigativa y reproductiva en un ambiente de confianza abierto a las opiniones de todas las mujeres. Se plantearon actividades que facilitaban la relación entre ellas con la intención de desarrollar una mente respetuosa, abierta y social. En cada sesión se ofreció un tiempo para la reflexión, a modo de feedback, en donde cada participante incorporaba los comentarios constructivos recibidos por parte del grupo. Se facilitó la expresión las emociones de las mujeres y la escenificación de situaciones en las que aparece el chantaje emocional con el objetivo de aprender a detectarlo para evitar la debilitación de la autoestima. Como afirma Bonia: 
"Con el taller de danza he empezado a poder expresar mis emociones. Para mí ha sido una buena oportunidad poder expresarme así ... he podido liberarme y expresar mis emociones, observar cómo me encuentro, expresar lo que quería decir que no dije. Siento que me he liberado emocionalmente". Comunica que quiere continuar bailando cuando salga de la Casa de Acogida porque le ayuda a sentirse mejor.

También, se practicaron técnicas de visualización y respiración para aprender a reconectar consigo mismas, gestionar y controlar estados de nerviosismo y pensamientos negativos reconduciéndolos hacia estados de calma y pensamientos positivos. Como resultado de las prácticas realizadas en el taller Jolette afirma: "Este taller me ha hecho sentir bien y recordar cuando bailaba. Sé que bailar me ayudaría a sentirme mejor y a ponerme en forma, me sentiría más ágil y más guapa. Estoy convencida de que cuando pueda asistir a clases de baile me voy a encontrar mejor, como cuando era más joven que practicaba normalmente deporte y bailaba. Me gusta bailar, me siento bien cuando bailo". Ella ha expresado su deseo de continuar bailando en cuanto consiga legalizar su titulación superior y reordenar su vida.

Igualmente, se promovieron los valores de reflexión, indagación, colaboración, igualdad y la no-discriminación. Se incluye, a modo de ejemplo, la percepción de una las participantes sobre las actividades realizadas en el taller de Danza Contemporánea dentro de la Casa.

He sentido que mi cuerpo podía moverse libre, como yo quería y me he divertido mucho por un momento. Me ha hecho sentir muy bien bailar, ... me he dejado llevar, he conseguido olvidarme de mis problemas. (Su cuerpo se muestra relajado y su cara expresa gran felicidad al decir estas palabras). (Silvín)

\section{Conclusión}

Los testimonios e historias de las mujeres inmigrantes que han sobrevivido a la violencia por parte de sus parejas confirman el estado de salud deteriorado de este colectivo que se manifiesta en: (a) el deseo de cambio para no ser lo que son ahora; (b) la dificultad para resolver ciertos problemas; (c) la auto-violación de su propia voluntad; (d) un autoconcepto deteriorado, sentimientos de infelicidad, tristeza y desesperanza; (e) falta de contacto físico con otras personas; y (f) reexperimentación de sensaciones extrañas al sentirse tocadas. En general, sus cuerpos se muestran descuidados, y en algunos casos abandonados.

La entrada en la Casa se realiza con un alto grado de estrés, con cierta confusión y expectativas a veces erróneas. Al tratarse de mujeres migrantes, muchas llegan sin su documentación porque les ha sido sustraída por los maltratadores para evitar que les abandonen. Acceden con diversas patologías, en una situación precaria. Sufren un alto grado de desajuste emocional y cierto desapego y dejadez con respecto a sus hijas/hijos, aunque no en todos los casos. Muestran cierta resistencia a las normas, e incluso actitudes desafiantes en algún caso. Se da una relajación generalizada pasadas las primeras sema- 
nas. Algunas, incluso con ayuda profesional, no logran entrar en la dinámica de la rutina diaria y tampoco consiguen una motivación suficiente para enfrentarse a sus problemas. Se evidencia una escasa formación.

La influencia del apoyo de todos los servicios recibidos en la Casa de Acogida es notable. En casi todos los casos las mujeres salen fortalecidas tras su paso por ésta y la mayoría comunican su agradecimiento a las trabajadoras. Muchas averiguan lo que les motiva a seguir adelante y luchan por ello. Se da un reconocimiento de sus capacidades y debilidades y también saben en qué deben mejorar. Se produce un reencuentro consigo mismas y con sus hijas/hijos. Son más conscientes de su situación, de sus emociones, de lo que quieren en su vida y de lo que deben rechazar, de que tienen una oportunidad para empezar casi desde cero con sus hijas/hijos y de que poseen nuevas estrategias para afrontar el día a día a pesar de su dura realidad. Hay un deseo generalizado de permanecer activas realizando tareas que les gustan, como la danza en algunos casos, por lo que se aprecia una mayor motivación por cuidarse más y sentirse bien. Antes de abandonar la Casa sufren estrés. Normalmente, al salir de ésta lo hacen esperanzadas, con mayor responsabilidad y casi siempre visiblemente más recuperadas. Desde ese momento aspiran a una mayor libertad y paz junto a sus hijas/ hijos y a encontrar una nueva vida mejor.

Financiación

Esta investigación recibió el apoyo de la Universidad de Alicante, a través de la ayuda de financiación recibida por el Vicerrectorado de Investigación al grupo "Diversidad, Educación y Género" (VIGROB-298).

\section{Referencias}

Abraham, MARgaret (2000). Isolation as a form of marital violence: The South Asian immigrant experience. Journal of Social Distress and the Homeless, 9, 221-236.

ABU-RAS, WAHIBA M. (2003). Barriers to services for Arab immigrant battered women in a Detroit suburb. Journal of Social Work Research and Evaluation, 4, 49-66.

Asociación pro Derechos Humanos Argituz (2015). Informe de identificación de necesidades y obstáculos encontrados por las mujeres víctimas de violencia de género del área rural de Bizkaia en el acceso efectivo a los servicios y prestaciones de apoyo, atención y justicia. Bilbao: Diputación Foral de Bizkaia y de la Asociación Argituz.

Bauer, Heidi M., Rodriguez, Michael, Szkupinski-Quiroga, Seline y Flores-Ortiz, YVETTE (2000). Barriers to health care for abused Latina and Asian immigrant women. Journal of Health Care for the Poor and Underserved, 11, 33-44.

Choice, Pamela y LAmke, Leanne K. (1997). A conceptual approach to understanding abused women's stay/leave decisions. Journal of Family Issues, 18, 290-314.

DAVIS, RuTH E. (2002). Leave-taking experiences in the lives of abused women. Clinical Nursing Research, 11, 285-305.

ECHEBURÚA, ENRIQUE. (2004): Superar un trauma: el tratamiento de las víctimas de sucesos violentos. Madrid: Pirámide. 
Instituto de la Mujer y para la Igualdad de Oportunidades (2018). Denuncias por discriminación por razón de género. http://institutoasturianodelamujer.com/iam/servicios-2/denuncias-por-discriminacion-por-razon-de-genero/

Keller, Elizabeth M. y Brennan, Pauline K. (2007). Cultural consideration and challenges to service delivery for Sudanese victims of domestic violence: Inshights from service providers and actors in the criminal justice system. International Review of Victimology, 14, 115-141.

Kelly, URsula A. (2009). I'am a mother first: The influence of mothering in the decisión making processes of battered immigrant Latino women. Research in Nursing and Health, 32, 286-297.

Kim, JinSEOK y GRAY, KAREN A. (2008). Leave or stay? Battered women's decision after intimate partner violence. Journal of Interpersonal Violence, 23, 1465-1482.

LATTA, RACHEl E. y Goodman, LiSA A. (2005). Considering the interplay of cultural context and service provision in intimate partner violence. Violence Against Women, 11, 1441-1464.

LeVenthal, Marcia B. (1980). Movement and growth: Dance therapy for special child. New York: Centre for Educational Research, New York University.

Ley Orgánica 1/2004, de 28 de diciembre, de Medidas de Protección Integral contra la Violencia de Género. Boletín Oficial del Estado, 313, de 29 de diciembre.

Ley 7/2012, de 23 de noviembre, de la Generalitat, Integral contra la Violencia sobre la Mujer en el Ámbito de la Comunitat Valenciana. Diario Oficial de la Generalitat Valenciana, 6912, de 28 de noviembre.

Lutenbacher, Melanie, Cohen, Alison y Mitzel, Julia (2003). Do we really help? Perspective of abused women. Public Health Nursing, 20, 56-64.

Mestre, Vicenta M., Tur, Ana M. y Samper, Paula (2008). Impacto psicosocial de la violencia de género en la mujeres y sus hijos e hijas: un estudio empírico en la Comunidad Valenciana. Valencia: Guada Impresores.

Murdaugh, Carolyn, Hunt, Salena, Sowell, Richard y Santana, Irma (2004). Domestic violence in Hispanics in the Southeastern United States: A survey and needs analysis. Journal of Family Violence, 19, 107-115.

Pastor Bravo, Mar (2015). Psiquiatría forense. Alicante: Servicio de Publicaciones de la Universidad de Alicante.

Rebollo Sánchez, Isabel y Bravo Campanón, Cristina. (2005). Casas de acogida: desde la experiencia a la reflexión. Cuadernos de Trabajo Social, 18, 317-332.

Short, Lynn M., McMahon, Pamela M., Chervin, Doryn D., Shelley, Gene A., Lezin, NicoLE E., Sloop, KiRA. S. y DAWKinS, Nicola. (2000). Survivors identification of protective factors and early warning signs for intimate partner violence. Violence Against Women, 6, 272-285.

Tran, Carolee. G. y Des Jardins, Kunya. (2000). Domestic violence in Vietnamese and Korean immigrant communities. En Jean. L. Chin (Ed.), Relationships among Asian American women (pp.71-96). Washington, DC: American Psychologicla Association. 
Vives-Cases, Carmen, Álvarez-Dardet, Carlos, Gil-González, Diana, Torrubiano-DoMÍNGUEZ, JoRdi, RohlfS, IzABELla y Escribà-AGÜIR, VicENTA. (2009). Perfil sociodemográfico de las mujeres afectadas por violencia del compañero íntimo en España. Gaceta Sanitaria, 23(5), 410-414.

WalkeR, L. (1979). The Battered Woman. New York, NY: Harper and Row.

Wolf, Marsha E., Ly Uyen, Hobart, Margaret. A. y Kerninc, Mary. A. (2003). Barriers to seeking police help for intimate partner violence. Journal of Family Violence, 18, 121-129. 